\title{
CLIMATOLOGIA DE CICLONES EXPLOSIVOS PARA A ÁREA CICLOGENÉTICA DA AMÉRICA DO SUL
}

\section{DANIEL PIRES BITENCOURT ${ }^{1}$; MÁRCIA VETROMILLA FUENTES ${ }^{2}$; CAMILA DE SOUZA CARDOSO $^{3}$}

\author{
${ }^{1}$ Fundação Jorge Duprat Figueiredo de Segurança e Medicina do Trabalho (FUNDACENTRO), \\ Florianópolis, SC, Brasil. \\ ${ }^{2}$ Instituto Federal de Educação, Ciência e Tecnologia de Santa Catarina (IFSC), Florianópolis, SC, Brasil. \\ ${ }^{3}$ Fundação de Apoio ao Desenvolvimento Rural Sustentável de Santa Catarina (FUNDAGRO), \\ Florianópolis, SC, Brasil.
}

daniel.bitencourt@pq.cnpq.br,marciaf@ifsc.edu.br,k_mila_krdoso@hotmail.com

Recebido Março de 2012 - Aceito Julho de 2012

\begin{abstract}
RESUMO
Ciclones extratropicais são classificados como "explosivos" quando a pressão central decresce $1 \mathrm{hPa} \mathrm{h}^{-1}$ em 24 h. Estes sistemas são importantes sobre a América do Sul devido aos fortes impactos sócioeconômicos. Esse artigo apresenta uma climatologia dos ciclones explosivos para a área ciclogenética da América do Sul, usando dados da reanálise do NCEP/NCAR de 1957 a 2010. A taxa de aprofundamento de um ciclone individual foi analisada com respeito a sua latitude média. Analisou-se vários aspectos, como frequência, gênese, trajetória e aprofundamento em $6 \mathrm{~h}$. Além disso, a profundidade, pressão central e raio dos ciclones explosivos foram comparadas com a climatologia de ciclones não explosivos. O campo de vento horizontal é comparado através de um sistema de coordenada móvel, no qual o centro do ciclone é posicionado no centro de um domínio de $30^{\circ}$ lat $\times 30^{\circ}$ lon. Constatou-se que os ciclones explosivos não ocorrem ao norte de $27^{\circ} \mathrm{S}$ e, em geral, iniciam sobre o oceano. Também observou-se que, em média, os ciclones explosivos são $5,1 \mathrm{hPa}$ mais profundos, possuem raio $0,41^{\circ}$ lat. maior e pressão central de $15,5 \mathrm{hPa}$ menor, em relação aos ciclones não explosivos. Além disso, os ciclones explosivos geram ventos médios de até $60 \%$ mais intensos que os demais ciclones. Palavras-chave: Ciclone Explosivo; América do Sul; Frequência; Trajetória
\end{abstract}

\begin{abstract}
CLIMATOLOGY OF EXPLOSIVE CYCLONES OVER CYCLOGENETIC AREA OF SOUTH AMERICA

Extratropical cyclones are defined as "explosive" when their deepening rate is maintained at $1 \mathrm{hPa} \mathrm{h}^{-1}$ during a 24-h period. Those systems are important over the South American continent due to their severe socio-economic impacts. This study presents a climatology of explosive cyclones over the cyclogenetic area of South America using NCEP-NCAR re-analysis data from 1957 to 2010. The deepening rate of an individual cyclone was classified with respect to their average latitude. Six-hourly storm attributes such as frequency, genesis, tracks, and deepening rates were analyzed. As a second step, their depth, central pressure, and radius were meaningfully compared with the climatological values obtained from non-explosive cyclones. Horizontal wind fields were compared through a co-moving coordinate system consisting of a $30^{\circ}$ lat $\times 30^{\circ}$ lon domain. It was found that the trajectory of most systems started over the ocean and that no explosive cyclones were found to occur at north of $27^{\circ} \mathrm{S}$. This study also highlights that, on average, explosive cyclones are $5.1 \mathrm{hPa}$ deeper, have a radius $0.41^{\circ}$ lat. larger, and a central pressure $15.5 \mathrm{hPa}$ lower than non-explosive cyclones. In addition, the data suggested that explosive cyclones were associated with wind speeds that were on average $60 \%$ stronger than non-explosive cyclones. Keywords: Explosive Cyclones; South America; Frequency; Tracks
\end{abstract}




\section{INTRODUÇÃO}

O tempo e consequentemente o clima do Hemisfério Sul (HS) são fortemente modulados pela ocorrência de ciclones extratropicais. Com base em climatologia do período de 19581997, Simmonds e Keay (2000b) constataram uma média de 35 a 38 sistemas ciclônicos (dependendo da estação do ano) por análise numérica sazonal no HS. Para a área ciclogenética da América do Sul considerada nesse estudo, entre $45^{\circ} \mathrm{S}$ e $15^{\circ} \mathrm{S}$ e entre $60^{\circ} \mathrm{W}$ e $20^{\circ} \mathrm{W}$, Sinclair (1994) mostrou que a densidade de ciclones (centros por circulo de 5 lat de raio) no inverno é de até aproximadamente 200 ciclones. Nesta área, os ciclones extratropicais atuam em todas as épocas do ano, mas com maior frequência no inverno (Gan e Rao, 1991; Sinclair, 1994, 1995; Mendes et al., 2010). Durante os meses de junho, julho e agosto, a densidade de sistemas ciclônicos é de aproximadamente $1 \times 10^{-3}$ ciclones ${ }^{\circ} \mathrm{lat}^{-2}$ maior do que nos demais meses do ano (Simmonds e Keay, 2000b).

Ainda considerando a área ciclogenética da América do Sul definida para esse estudo, a profundidade média dos ciclones encontrada por Simmonds e Keay (2000b) foi de 2,5 a 3,5 hPa nos meses de dezembro, janeiro e fevereiro e de 3,0 a 4,0 hPa nos meses de junho, julho e agosto. Dependendo dos valores da profundidade e da distância entre o centro dos sistemas e a costa da região Sul do Brasil, os ciclones que atuam nessa área ciclogenética provocam consideráveis velocidades de vento no litoral dessa região, especialmente ao sul de $28^{\circ} \mathrm{S}$ (Bitencourt et al., 2010), podendo causar prejuízos sociais e econômicos.

Pode-se considerar dois fatores como sendo responsáveis pela área ciclogenética abordada nesse estudo. O primeiro, considerado como fundamental para o desenvolvimento ciclogenético, principalmente nos meses de inverno, é a instabilidade baroclínica. O segundo fator diz respeito as trocas de energia entre a superfície e a atmosfera. A corrente do Brasil pode contribuir para a maior frequência e intensificação desses sistemas no Atlântico Sul (Sinclair, 1994, 1995; Vera et al., 2002). Smith (2000) mostrou que a distribuição horizontal do aquecimento é importante para o desenvolvimento de ciclones. Essa distribuição do aquecimento, quando caracteriza-se por altos gradientes horizontais de temperatura, tais como $0,3{ }^{\circ} \mathrm{C}$ $\mathrm{km}^{-1}$, conforme encontrado por Pezzi et al. (2009) na confluência das correntes Brasil-Malvinas, tem relação com os fluxos de calor latente e sensível entre a superfície oceânica e a atmosfera, os quais contribuem para o desenvolvimento de ciclones (Nuss e Anthes, 1987; Davis e Emanuel, 1988; Crescenti e Weller, 1992; Neiman e Shapiro, 1993; Saraiva, 1996; Piva, 2001 e Piva et al., 2008 e 2011). Além disso, há a influência da Cordilheira dos Andes (Satyamurty et al., 1980; Gan e Rao, 1994; Sinclair, 1995; Seluchi et al., 1998; Seluchi e Saulo, 1998; Vera et al., 2002; Miky-Funatsu et al., 2004; Hoskins e Hodges,
2005; Mendes et al., 2007), visto que a vorticidade ciclônica associada com o distúrbio transiente perde intensidade ao se aproximar dos Andes devido a redução da coluna atmosférica (Hoskins, 1997), voltando a se intensificar após ultrapassar a cordilheira. Considerando um escoamento adiabático e zonal (vorticidade relativa nula, $\zeta=0$ ) de oeste, há um esticamento da coluna atmosférica antes de se aproximar dos Andes, ou seja, a variação da temperatura potencial na vertical diminui e a vorticidade potencial, dada pela soma das vorticidades relativa e planetária, $|(\zeta+f)|$, aumenta. Como em um escoamento zonal $f$ é constante, $|\zeta|$ aumenta tornando o escoamento um pouco ciclônico, no caso do HS, antes de atingir os Andes. Com esse desvio do escoamento para sul, $|f|$ aumenta fazendo com que a $|\zeta|$ pare de aumentar. No topo dos Andes, a coluna atmosférica diminui, a $\zeta$ torna-se anticiclônica e o escoamento passa a fluir em direção ao equador. Após cruzar os Andes, quando a coluna atmosférica atinge sua profundidade normal, o escoamento encontra-se em latitudes relativamente baixas fazendo com que a $\zeta$ torne-se ciclônica novamente. Na sequência, o escoamento persiste numa trajetória ondulatória no plano horizontal. Dessa forma, um escoamento permanente de oeste cruzando os Andes resulta em um padrão ciclônico imediatamente a leste da cordilheira, contribuindo para o desenvolvimento de ciclones na área ciclogenética definida para este estudo.

Dentre os eventos ciclogenéticos que ocorrem no mundo, alguns possuem desenvolvimento diferenciado e são chamados de ciclones explosivos ou "bombas". Os ciclones explosivos (CEx), formados pela combinação do processo baroclínico somado a outros mecanismos (Roebber, 1984), se caracterizam pela rápida redução da pressão central e aumento na sua intensificação que, segundo Lim e Simmonds (2002), dificultam o prognóstico e podem causar sérias ameaças à vida humana e a propriedade em áreas próximas à costa ou de navegação. Vários autores são motivados a estudar esse tipo de sistema devido ao tempo severo a eles associados e ao entendimento das estruturas dinâmicas e termodinâmicas da atmosfera, visto que os $C E x$ são raros em comparação com os ciclones de desenvolvimento não explosivo. Em todo o HS ocorrem em média $26 C E x$ por ano, sendo a maior frequência no trimestre de junho, julho e agosto (Lim e Simmonds, 2002). Allen et al. (2010) apresentaram uma climatologia global de $C E x$ utilizando quatro reanálises diferentes e também identificaram esse trimestre como o mais frequente.

Nas últimas décadas, vários autores têm pesquisado os $C E x$ sob muitos aspectos, tais como, o entendimento das estruturas físicas através de simulações numéricas, estudos climatológicos e estatísticos e, ainda, por meio de estudos de caso. Existem mais publicações sobre CEx para o Atlântico Norte (Kuo et al., 1991; Kuo e Nam, 1990; Lackmann et al., 1996; Manobianco, 1989a, 1989b; Sanders, 1986; Lupo et al., 
1992; Wang e Rogers, 2001) em comparação ao número de publicações voltadas ao Atlântico Sul. Jusem e Atlas (1991) realizaram um estudo diagnóstico de um caso de ciclone explosivo ocorrido em maio de 1984 e Seluchi e Saulo (1998) estudaram os possíveis mecanismos envolvidos com uma ciclogênese explosiva. Os casos estudados por Jusem e Atlas (1991) e Seluchi e Saulo (1998), ambos para a América do Sul, apesar de terem apresentado características de rápido desenvolvimento, não foram identificados como $C E x$ no presente estudo.

Para outras partes do mundo também foram feitos estudos sobre o desenvolvimento explosivo de ciclones. Chen et al. (1992) estudaram a climatologia de $C E x$ no leste da Ásia e região costeira e encontraram uma possível correlação entre frequência de eventos e episódios de El Niño. Chen e Lu (1997) estudaram aspectos climatológicos dos $C E x$ no oeste do Pacífico Norte e áreas costeiras do leste da Ásia. Colluci e Alberta (1996) estudaram a relação entre as ciclogêneses explosivas com episódios de bloqueio no Hemisfério Norte (HN). Yoshida e Asuma (2004) classificaram os ciclones com pequena, moderada e forte taxa de aprofundamento no nordeste do Pacífico e, posteriormente, Yoshida e Asuma (2008) investigaram os casos extremos de cada tipo de ciclone explosivo através de simulações numéricas. Kouroutzoglou et al. (2010) construíram uma climatologia objetiva de CEx para a região Mediterrânea com 40 anos de dados da reanálise do ERA-40 e identificaram uma frequência de 5,5 sistemas por ano. Gyakum e Danielson (2000) compararam a dinâmica e termodinâmica entre ciclogêneses explosivas e não explosivas no setor oeste do Pacífico Norte.

Nesse artigo, apresenta-se um estudo climatológico das ciclogêneses explosivas, identificadas no período de 1957 a 2010 sobre a área em estudo. Essa área engloba uma das regiões de maior frequência de ciclogênese encontradas por Gan e Rao (1991), Sinclair (1995) e Simmonds e Keay (2000b). Allen et al. (2010) identificaram essa área como sendo a de maior frequência de sistemas explosivos de todo o $\mathrm{HS} \mathrm{e}$, considerando apenas o continente sul-americano, Allen et al. (2010) também identificaram uma área ciclogenética no extremo sul da América do Sul, detectada principalmente nas reanálises JRA-25 e ERAInterim. Entretanto, essa área ciclogenética não é avaliada nesse estudo. $\mathrm{O}$ objetivo principal desse artigo é identificar a época de maior frequência e as trajetórias preferenciais dos $C E x$, que ocorrem na área ciclogenética da América do Sul. Em relação ao trabalho de Lim e Simmonds (2002), o presente estudo utiliza diferentes base de dados e período de análise. Além disso, nesse estudo considera-se períodos de $24 \mathrm{~h}$ com desenvolvimento explosivo iniciando em qualquer horário da reanálise, enquanto que Lim e Simmonds (2002) identificaram os CEx iniciando sempre as 0000 UTC. Análises quantitativas mostram o comportamento médio mensal da variação da pressão central a cada $6 \mathrm{~h}$ do desenvolvimento explosivo. Os $C E x$ são comparados com os ciclones não explosivos através da análise da pressão central, profundidade, raio médio e dos campos de velocidade do vento em torno do centro dos sistemas.

\section{DADOS E METODOLOGIA}

\subsection{Dados}

Foram utilizados dados de pressão ao nível médio do mar $(p)$ e velocidade do vento $(V)$ em $1000 \mathrm{hPa}$ da reanálise do National Centers for Environmental Prediction / National Center for Atmospheric Research (NCEP/NCAR). Esses dados possuem resolução espacial de $2,5^{\circ}$ de latitude e longitude e resolução temporal de $6 \mathrm{~h}(00,06,12$ e 18 UTC) (Kalnay et al., 1996). A reanálise do NCEP/NCAR é obtida através de dados meteorológicos de superfície em terra, navios, radiossondas, aeronaves, satélites e outros meios, sendo que o controle de qualidade e assimilação desses dados é realizado pelo mesmo sistema desde 1957. Por isso, para esse estudo, a série analisada compreende o período de 1 de janeiro de 1957 a 31 de dezembro de 2010.

\subsection{Identificação de toda população de ciclones}

Primeiramente foram identificados todos os ciclones extratropicais no domínio entre as latitudes de $45^{\circ} \mathrm{S}$ a $15^{\circ} \mathrm{S}$ e as longitudes de $60^{\circ} \mathrm{W}$ a $20^{\circ} \mathrm{W}$ (Figura 1). Utilizou-se o esquema automático de identificação e monitoramento de ciclones desenvolvido na Universidade de Melbourne (Murray e Simmonds, 1991), que requer apenas o campo de pressão ao nível médio do mar $(p)$. O algoritmo utilizado nesse trabalho foi aperfeiçoado no final da década de 90 e todos os detalhes do método e de suas melhorias são mostrados por Simmonds e Murray (1999) e Simmonds et al. (1999). Uma das principais vantagens da identificação automática dos sistemas em dados dispostos em pontos de grade é a utilização de técnicas objetivas com base em informações uniformes ao longo do tempo.

Para este trabalho, o algoritmo foi definido para identificar apenas os sistemas ciclônicos fechados em superfície. Também foram descartados os sistemas com duração inferior a $24 \mathrm{~h}$ dentro do domínio mostrado na Figura 1. Simmonds e Murray (1999) trataram o Laplaciano da pressão na vizinhança do centro do ciclone $\left(\nabla^{2} p=\partial^{2} p / \partial x^{2}+\partial^{2} p / \partial y^{2}\right)$ como uma medida da força do sistema, classificando como "fortes" os sistemas com $\nabla^{2} p>0,7 \mathrm{hPa}^{\circ} \mathrm{lat}^{-2}$ e como "fracos" os sistemas com $0,2<\nabla^{2} p<0,7 \mathrm{hPa}^{\circ} \mathrm{lat}^{-2}$. Considerando essa classificação, nesse estudo são descartados os sistemas com $\nabla^{2} p<0,2 \mathrm{hPa}^{\circ}{ }^{\circ} \mathrm{lat}^{-2}$, e $\Delta \mathrm{x}$ e $\Delta \mathrm{y}$ utilizados foram iguais a $5^{\circ} \mathrm{de}$ latitude e longitude, respectivamente. 


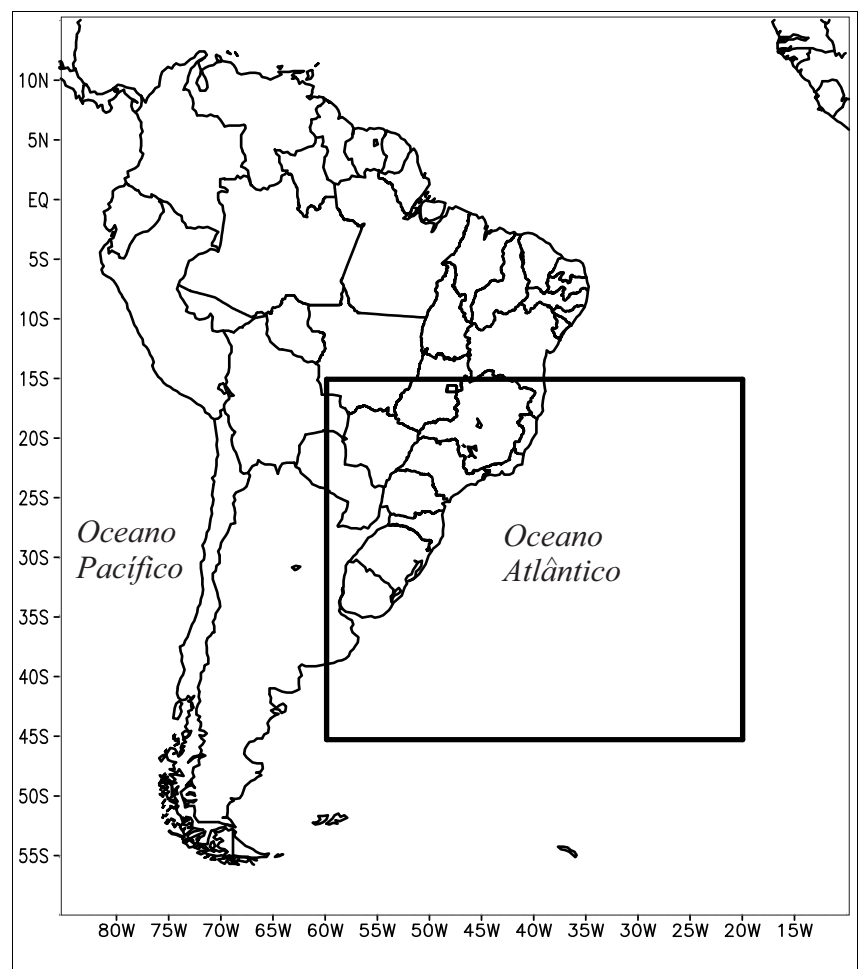

Figura 1 - O quadrado destacado por linhas contínuas indica o setor da América do Sul e Oceano Atlântico definido para identificação dos ciclones.

Apesar do $\nabla^{2} p$ ser importante, este parâmetro apresenta dependência implícita da escala horizontal. Um ciclone, com um dado valor de $\nabla^{2} p$, será tão mais intenso, quanto menor for a escala horizontal desse sistema (Simmonds e Keay, 2000a). Assim, outros parâmetros, como a profundidade $(D)$ e raio $(R)$ dos ciclones tornam-se necessários para a análise. Todos esses parâmetros são relacionados através da Equação 1:

$$
D=\frac{1}{2} \frac{\partial^{2} p}{\partial r^{2}} R^{2}=\frac{1}{4} \nabla^{2} p R^{2}
$$

onde $\nabla^{2} p$ é o valor médio do Laplaciano da pressão numa área correspondente a região que cerca o máximo $\nabla^{2} p$, em que o $\nabla^{2} p$ é positivo. A distância média, em ${ }^{\circ}$ lat, entre o centro do sistema e o limite dessa área $\left(\nabla^{2} p>0\right)$ é o $R$ do sistema.

Além da $D$ e $R$, o esquema automático de identificação de Murray e Simmonds (1991) também gera para cada tempo da reanálise a pressão central $\left(p_{c}\right)$, latitude (lat) e longitude (lon) do ciclone. A partir das informações de lat e lon obteve-se a velocidade de deslocamento dos sistemas.

Uma vez identificados os ciclones e calculados os parâmetros supracitados, foram gerados campos de velocidade horizontal do vento $(V)$ em torno do centro de cada sistema, para cada horário (intervalos de $6 \mathrm{~h}$ ) e com a mesma resolução espacial da reanálise do NCEP/NCAR. O centro do ciclone foi determinado como sendo o ponto de grade mais próximo da lat e lon centrais do ciclone, conforme identificado pelo esquema de Murray e Simmonds (1991). Posteriormente, calculou-se os campos médios de $V$ para toda a população de ciclones e exclusivamente para os ciclones explosivos. Os campos de $V$ foram gerados através de um sistema de coordenada móvel, que consiste de um domínio com dimensões de $30^{\circ}$ lat $\times 30^{\circ}$ lon . Assim, o comportamento da $V$ ao redor do centro do ciclone é avaliado, desconsiderando a região de atuação do sistema. Manobianco (1989a) utilizou técnica similar para estudar ciclogêneses explosivas no Atlântico Norte.

\subsection{Identificação dos ciclones explosivos}

Todos os ciclones extratropicais, identificados através do esquema de Murray e Simmonds (1991), foram submetidos ao método proposto por Sanders e Gyakum (1980), onde o desenvolvimento do ciclone é expresso pela Taxa Normalizada de Aprofundamento da pressão central $\left(T N A_{c}\right)$, dada por

$$
T N A_{c}=\frac{\Delta p_{c}}{24 h P a} \frac{\operatorname{sen} 60}{|\operatorname{sen} \varphi|}
$$

onde $\Delta p_{c}$ é a variação da pressão central do ciclone em $24 \mathrm{~h}$ e $\varphi$ é a latitude média de localização do centro do sistema, considerando os pontos inicial e final da trajetória em períodos de $24 \mathrm{~h}$.

O cálculo foi também realizado usando o método proposto por Lim e Simmonds (2002), no qual o desenvolvimento explosivo é representado pela Equação 2, mas substituindo a pressão central $\left(p_{c}\right)$ pela pressão central relativa $\left(p_{r}\right)$, sendo $p_{r}=p_{c}-p_{c l i}$, onde $p_{c l i}$ é o valor climatológico da pressão central obtida do campo de pressão climatológica diária da reanálise do NCEP/NCAR. A $p_{c l i}$ foi interpolada para a mesma lat e lon do centro do ciclone, ou seja, o valor da $p_{c l i}$ é ajustado exatamente para o ponto do centro do ciclone, com base nos valores obtidos dos quatro pontos de grade ao redor. Assim, a Taxa Normalizada de Aprofundamento da pressão central relativa $\left(T N A_{r}\right)$ é definida como:

$$
T N A_{r}=\frac{\Delta p_{r}}{24 h P a} \frac{\operatorname{sen} 60}{|\operatorname{sen} \varphi|}
$$

onde $\Delta p_{r}$ é a variação da pressão central relativa do ciclone em $24 \mathrm{~h}$.

Quando as medidas de $T N A_{c}$ ou $T N A_{r}$ excedem uma unidade [1 "Bergeron", de acordo com a terminologia de Sanders e Gyakum (1980)], o sistema tem um desenvolvimento explosivo ou "bomba". Sanders (1986) classificou a intensidade dos CEx como "fracos" $(1,0 \leq$ Bergeron $\leq 1,2)$, "moderados" $(1,3 \leq$ Bergeron $\leq 1,8)$ e "fortes" (Bergeron $>1,8)$.

Lim e Simmonds (2002) apresentaram uma discussão abrangente sobre o uso da pressão climatológica na identificação 
de ciclogêneses com rápido aprofundamento. De acordo com Simmonds e Wu (1993) e Sinclair $(1995,1997)$, há vantagens em analisar ciclogêneses explosivas utilizando a pressão relativa (Equação 3). Segundo Sinclair (1995), alguns ciclones podem alcançar uma taxa de aprofundamento maior do que 1 Bergeron, mas com pouco ou nenhum aumento na vorticidade ciclônica. $\mathrm{O}$ aprofundamento do sistema ocorre simplesmente porque o ciclone se move, durante um período de $24 \mathrm{~h}$, em direção a uma área com pressões mais baixas. Jones e Simmonds (1993) e Simmonds e Keay (2000a) mostraram que muitos ciclones do HS se desenvolvem em latitudes médias e migram para sudeste, passando por fortes gradientes meridionais de pressão climatológica. Considerando isso, a climatologia apresentada a partir da seção 3.2 desse estudo tem como base apenas os $C E x$ identificados através da metodologia $T N A_{r}$. Entretanto, com intuito de reforçar as diferenças de resultados obtidos pelas duas metodologias, na primeira seção de resultados e discussão (seção 3.1) analisa-se e compara-se ambos os métodos, $T N A_{c}$ e $T N A_{r}$.

\section{RESULTADOS E DISCUSSÃO}

\subsection{Frequências mensais e intensidade dos ciclones explosivos}

A análise das metodologias $T N A_{c}$ e $T N A_{r}$ mostram que as frequências de ciclones explosivos na região de estudo apresentam um rápido crescimento a partir do mês de janeiro, mês de menor frequência de ocorrência de todo o ano, com um máximo no mês de junho e um decréscimo um pouco mais lento a partir deste mês (Figura 2a). Estes resultados são concordantes com os encontrados para todo o HS por Allen et al. (2010), os quais demonstram que ciclones explosivos ocorrem preferencialmente nos meses de inverno, seguido de primavera, depois de outono e por fim de verão. De acordo com Lim e Simmonds (2002), os CEx que ocorrem no leste do Uruguai podem ocorrer durante todo o ano, no entanto são dominantes na estação de inverno. Roebber (1984) sugere que a maioria dos $C E x$ possuam origem em mecanismos provocados pela instabilidade baroclínica. Entretanto, de acordo com os resultados encontrados por Piva et al. (2008, 2011), obtidos a partir de simulações numéricas, os fluxos de calor latente e sensível no Oceano Atlântico Sul, próximos à costa do sul do Brasil e Uruguai, possuem influência decisiva na intensidade dos ciclones. De acordo com Piva et al. $(2008,2011)$, as trocas de energia entre o oceano e a atmosfera nessa região ciclogenética da América do Sul são importantes antes da fase de mais rápido desenvolvimento do ciclone, preparando o ambiente, através da maior disponibilidade de energia e umidade, para uma ciclogênese mais intensa.

No presente estudo, aplicando as metodologias $T N A_{c}$ e $T N A_{r}$, foram identificados, em média, 2,7 e 1,57 CEx por ano, respectivamente. Se compararmos o número de $C E x$ identificados através de $T N A_{c}$ (144 eventos) e $T N A_{r}$ ( 85 eventos) com toda a população de ciclones extratropicais (3.483 eventos) identificados através da metodologia apresentada na seção 2.2, pode-se considerar que os $C E x$ são raros na América do Sul. Os $C E x$ representam uma taxa de 4,1\% (utilizando $T N A_{c}$ ) e 2,4\% (utilizando $T N A_{r}$ ) do total de ciclones. Entretanto, apesar da taxa de ocorrência dos $C E x$ ser baixa, a área ciclogenética abordada nesse estudo é a área de maior frequência de $C E x$ do HS (Allen et al., 2010).

Utilizando-se a classificação de Sanders (1986), para os 85 casos identificados nesse estudo através da metodologia $T N A_{r}$, encontrou-se a grande maioria, cerca de $81 \%$, como sistemas "fracos" (Figura 2b). Aproximadamente 16,5\% dos CEx foram classificados como "moderados" e apenas 2 eventos explosivos "fortes" ocorreram na área ciclogenética da América do Sul, o que representa cerca de $2,5 \%$ de todos os eventos
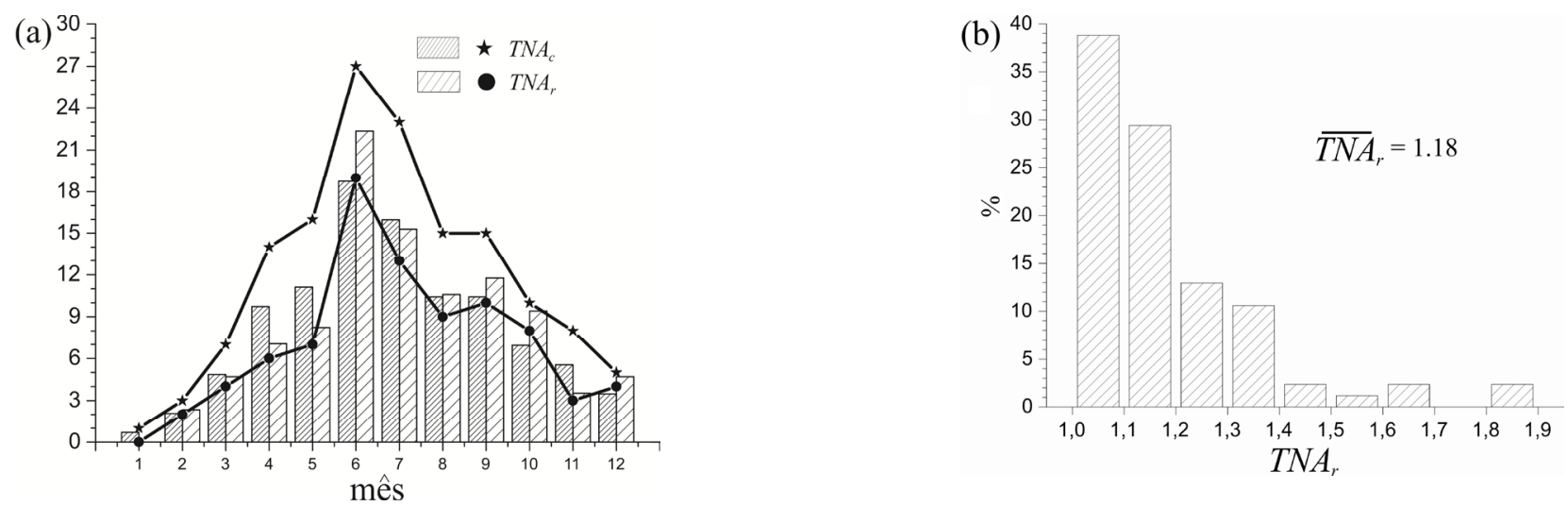

Figura 2 - (a) Número (linhas) e frequência (barras) mensal de CEx identificados através dos métodos $T N A_{c}$ e $T N A_{r}$. A escala no eixo vertical do gráfico é adimensional para a representatividade do número mensal de $C E x$ e em \% para representatividade da frequência mensal de $C E x$. (b) Frequência em \% de ocorrência de $C E x$, por faixa de valores de $T N A_{r}$. 
(Figura 2b). Os dois casos de CEx "fortes" foram registrados em julho de 1970, com $T N A_{r}=1,85$, e em dezembro de 2003, com $T N A_{r}=1,82$. Resultados semelhantes foram encontrados por Lim e Simmonds (2002) em uma climatologia para o HS, onde 87 \% são CEx "fracos", 12 \% "moderados" e 1 \% "fortes".

Nesse estudo, todos os casos de ciclogênese que foram identificadas como explosivas através do método $T N A_{r}$, foram também identificadas como explosivas através do método $T N A_{c}$. Entretanto, dependendo da configuração do campo climatológico de pressão e da direção de deslocamento do sistema, um $C E x$ pode ser identificado por $T N A_{c}$ e não por $T N A_{r}$. Allen et al. (2010) mostraram dois casos de ciclogêneses, um para cada hemisfério, em que ambos os casos foram considerados $C E x$, quando o campo de pressão é subtraído do campo climatológico $\left(T N A_{r}\right)$, mas não foram identificados como $C E x$, quando foi considerado apenas o campo de pressão $\left(T N A_{c}\right)$. Aqui, a análise feita para a região ciclogenética da América do Sul mostrou que a principal diferença entre as metodologias $T N A_{c}$ e $T N A_{r}$ não é com respeito a variabilidade anual da frequência mensal, e sim quanto ao número de $C E x$ identificados. Considerando a metodologia $T N A_{r}$ (Equação 3), o número de CEx identificados diminui de 144 para 85 eventos, uma diminuição de aproximadamente $41 \%$. Essa diferença é esperada, visto que o setor mais ao sul da área utilizada nesse estudo é caracterizado por intensos gradientes horizontais de pressão.

\subsection{Gênese e trajetória}

Geralmente os $C E x$ (identificados por $T N A_{r}$ ) possuem deslocamento para sudeste, assim como é verificado para a climatologia de toda população de ciclones extratropicais (Gan e Rao, 1991; Simmonds e Keay, 2000a) (Figuras 3-6). Nesse estudo, a velocidade média de deslocamento encontrada durante a trajetória explosiva foi de 13,8 $\mathrm{m} \mathrm{s}^{-1}$. Reboita (2008) encontrou que os ciclones da costa sul/sudeste do Brasil deslocam-se com velocidade média de $9 \mathrm{~m} \mathrm{~s}^{-1}$. Em algumas ocasiões, foram verificados trechos de $6 \mathrm{~h}$ com uma pequena componente de deslocamento para oeste. Esses deslocamentos para oeste podem ser devido a existência de dois ciclones próximos, situação que favorece um giro horário entre os dois sistemas. Dessa forma, o ciclone que está mais ao sul desloca-se para oeste e o que está mais a norte desloca-se para leste. Outra situação que pode explicar o deslocamento para oeste é quando, em um determinado horário, existe uma grande área com pressões mais baixas e fraco gradiente de pressão, ou seja, apesar de ainda não estar completamente configurado, o sistema ciclônico existe e, portanto, o esquema de identificação detecta um ponto de pressão mínima, identificando esse ponto como o local do centro do ciclone. Quando, no próximo horário da reanálise, ocorre aprofundamento do campo de pressão em um local mais a oeste do ponto identificado anteriormente, o esquema automático de identificação detectará o centro do sistema também mais a oeste, mostrando assim um deslocamento em $6 \mathrm{~h}$ com componente oeste. Na sequência, quando o ciclone está mais bem configurado, o sistema, de fato, passa a se deslocar com uma componente de leste. Essa situação foi verificada na trajetória dos $C E x$ que ocorreram em junho de 1983 e em agosto de 2007.

Também constata-se que quase a metade dos $C E x$, cerca de $49,4 \%$, apresentam toda trajetória sobre o oceano e outros 23,5\% apresentam início da ciclogênese sobre o continente, mas passam a ser considerados explosivos somente sobre o oceano, totalizando uma taxa de $72,9 \%$ de ciclones que iniciam o desenvolvimento explosivo sobre o oceano. Dos demais $C E x$ identificados nessa área, cerca de 22,4 \% iniciam sua trajetória já com características explosivas $\left(T N A_{r} \geq 1\right)$ sobre o continente e cerca de $4,7 \%$ iniciam a trajetória como um ciclone não explosivo, passando a ser explosivos ainda sobre o continente. Os meses de junho e agosto (Figuras 5a e 5c) apresentam
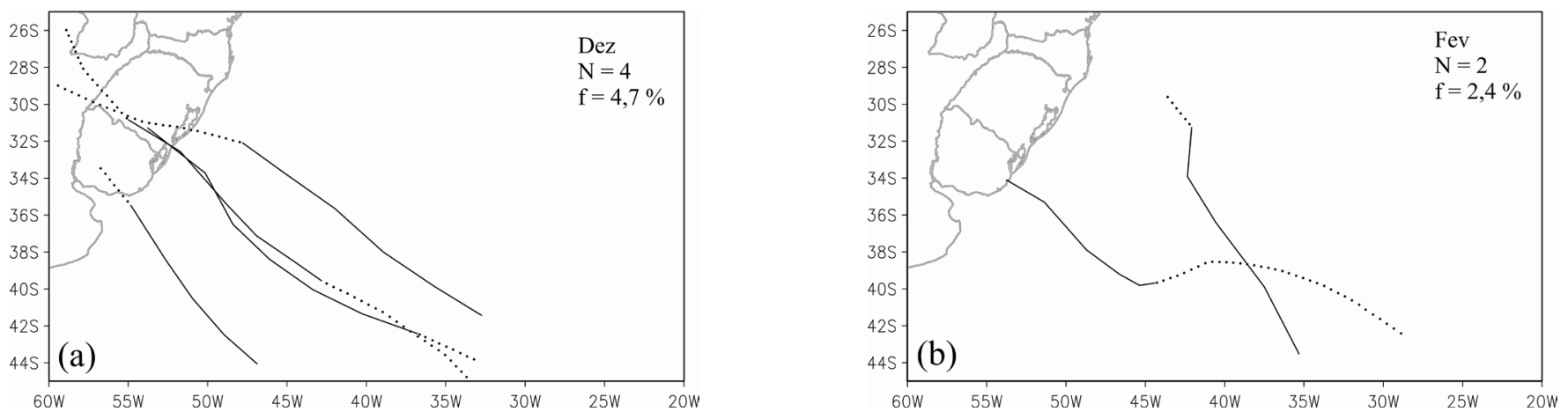

Figura 3 - CEx (identificados por $T N A_{r}$ ) nos meses de (a) dezembro e (b) fevereiro, no período de 1957 a 2010 . As linhas tracejadas e contínuas mostram a trajetória completa dos ciclones. A linha contínua mostra exclusivamente a trajetória com desenvolvimento explosivo. N é o número e f é a frequência de $C E x$ no mês. Os mapas não mostram a faixa latitudinal entre 25 e $15^{\circ} \mathrm{S}$ porque não foram identificados $C E x$ nessa área. 

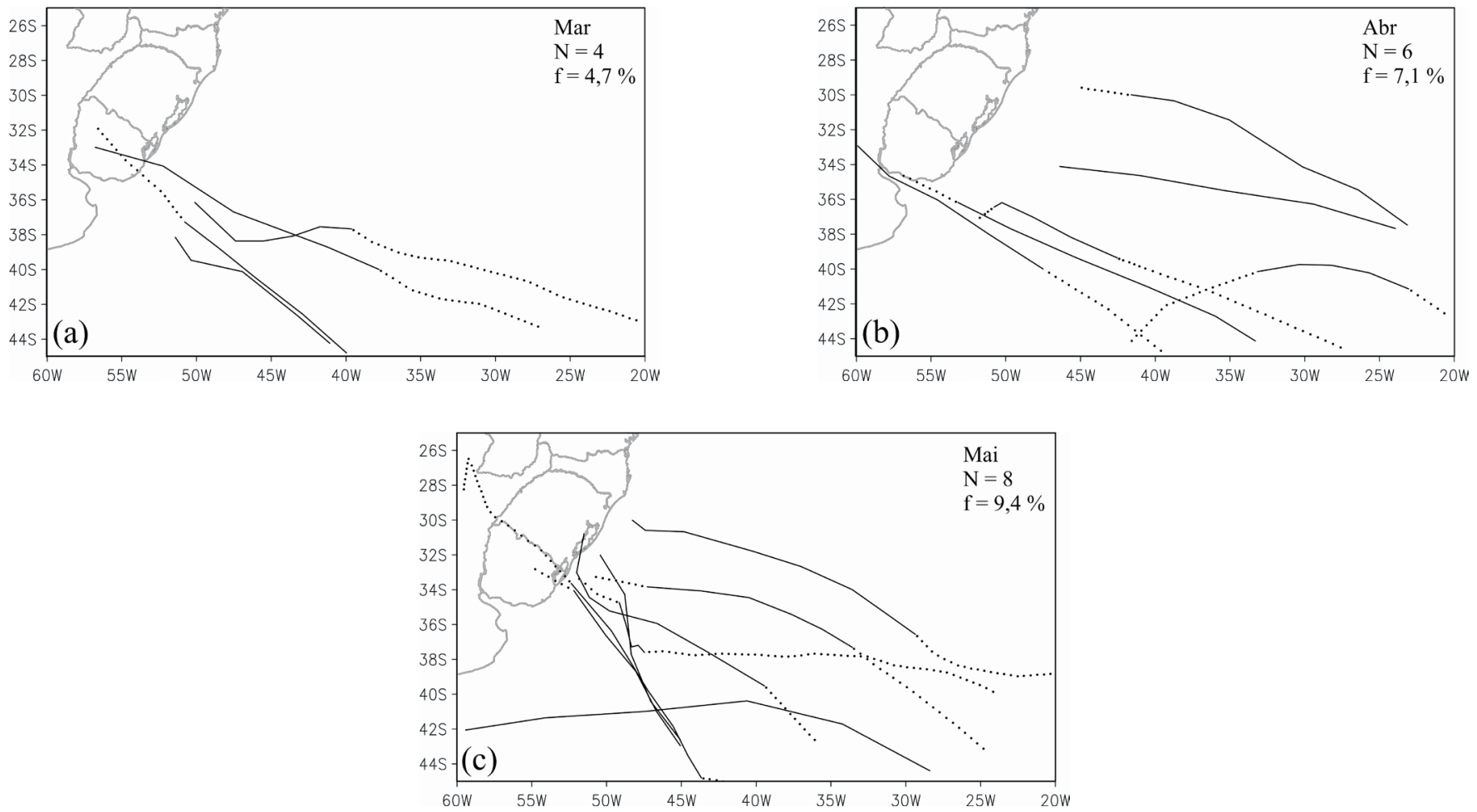

Figura 4 - Mesmo que a figura 3, mas para os meses de (a) março, (b) abril e (c) maio.
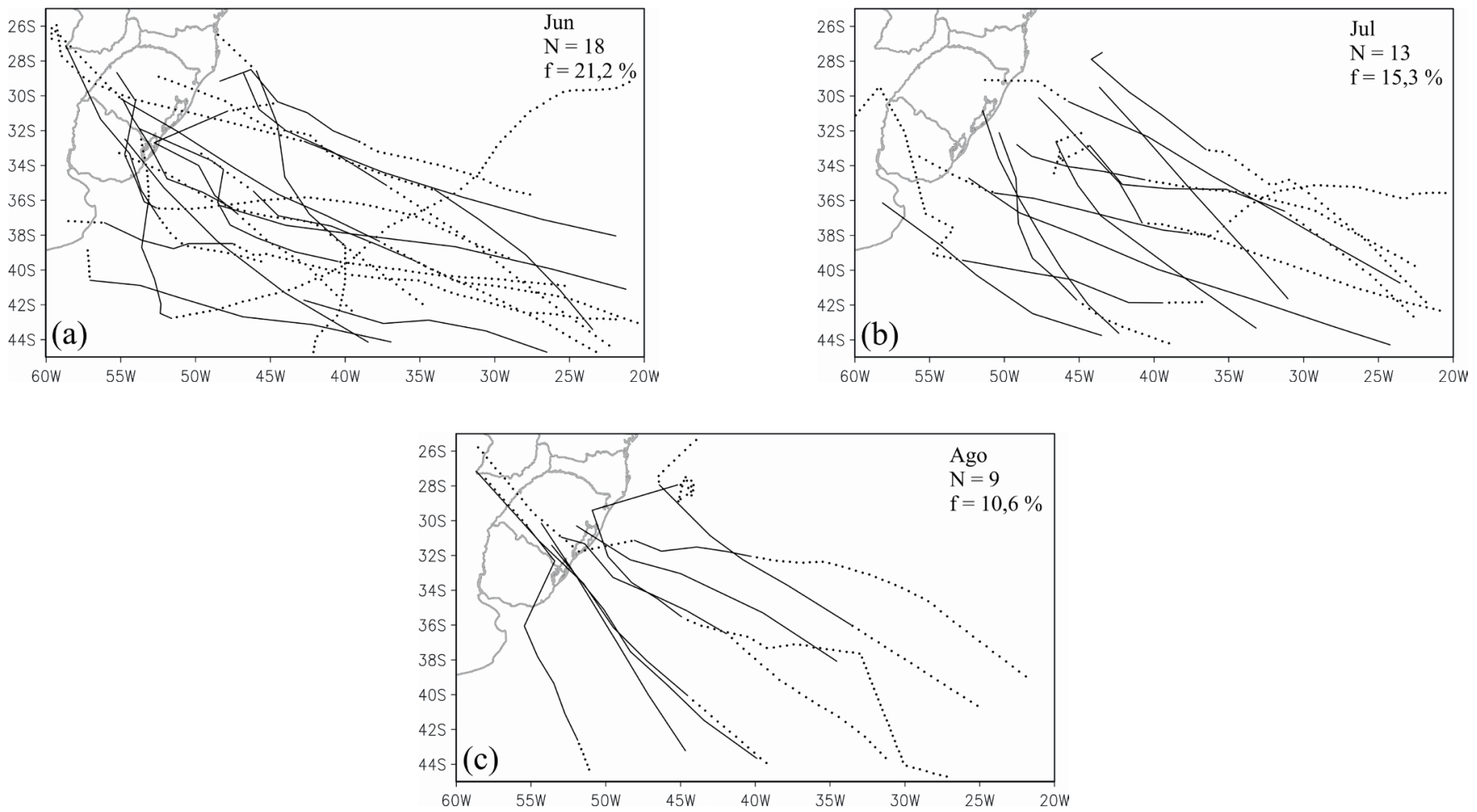

Figura 5 - Mesmo que a figura 3, mas para os meses de (a) junho, (b) julho e (c) agosto. 

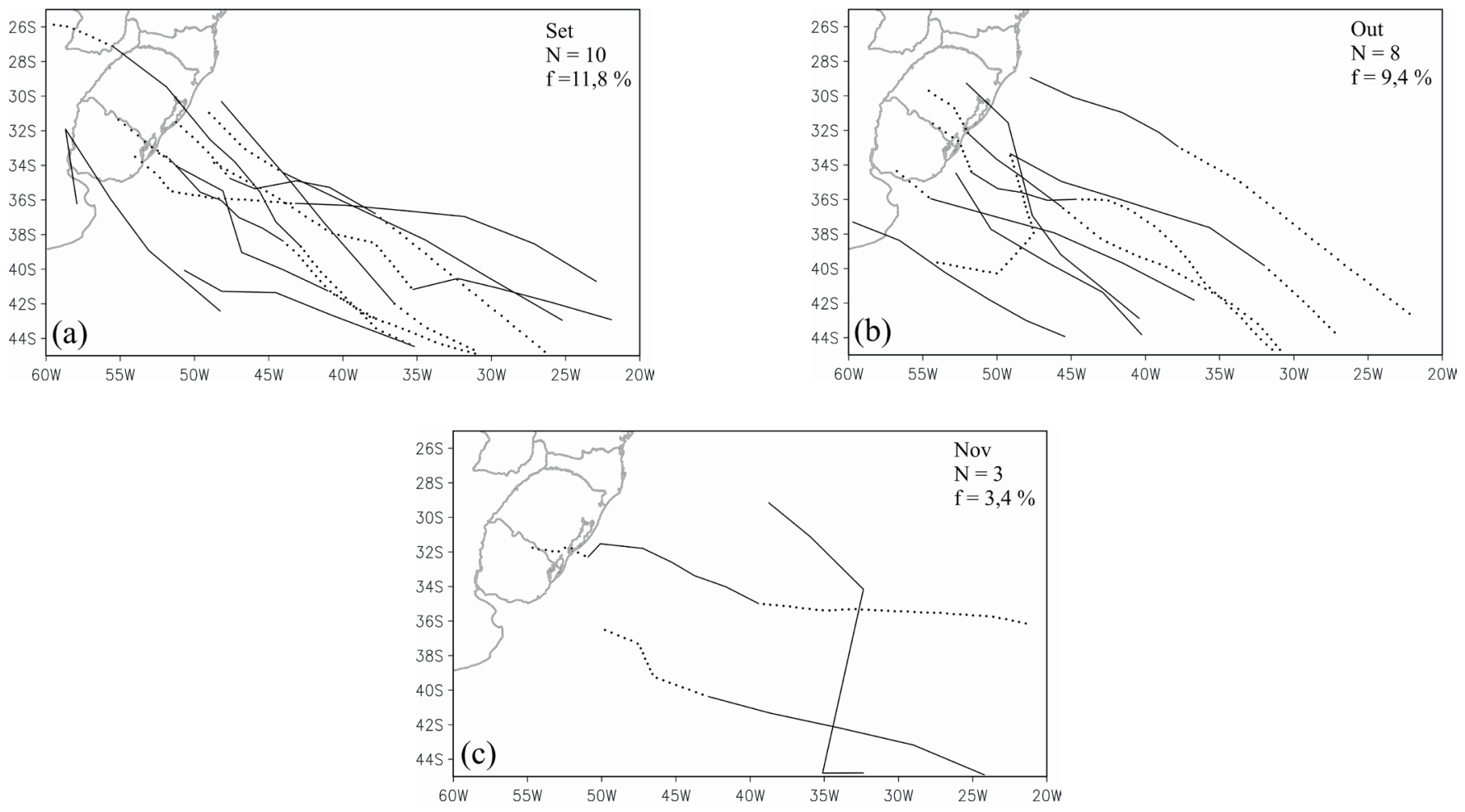

Figura 6 - Mesmo que a figura 3, mas para os meses de (a) setembro, (b) outubro e (c) novembro.

um maior número de $C E x$ com gênese continental. Sanders e Gyakum (1980) também constataram através de estudo sinóticodinâmico, que os $C E x$ são fenômenos predominantemente marítimos e de estação fria. A ocorrência de CEx especialmente sobre o oceano (Figuras 3-6) indica que a troca de energia entre a superfície e a baixa atmosfera é importante (Kuo et al., 1991).

O fato da gênese "explosiva" dos sistemas ciclônicos ocorrer sobre o continente predominantemente nos meses mais frios, sugere a importância da baroclinicidade atmosférica, assim como, da posição e intensidade do jato subtropical. A combinação das forçantes geradas pela liberação de calor latente, trocas de energia entre a superfície e a atmosfera, topografia e distúrbios de altos níveis favorecem o desenvolvimento das chamadas ciclogênese de costa leste. Por outro lado, a constatação de que a maioria dos $C E x$ são marítimos, aponta para a importância das trocas de calor entre a superfície e a baixa atmosfera como fonte de energia para a intensificação desses sistemas.

O gráfico da Figura 7 sintetiza o posicionamento geográfico da gênese "explosiva", ou seja, a posição média, mais ao norte e mais ao sul do início da trajetória dos ciclones com desenvolvimento explosivo $\left(T N A_{r} \geq 1\right)$. Percebe-se que durante o ano, em média, o início do desenvolvimento dos $C E x$ ocorre na faixa longitudinal de $53^{\circ} \mathrm{W}$ a $44^{\circ} \mathrm{W}$, sem apresentar uma posição preferencial em meses frios ou quentes (Figura 7a). Por outro lado, a média mensal da latitude mostra que o inicio do desenvolvimento explosivo ocorre mais ao sul $\left(36^{\circ} \mathrm{S}\right)$ no mês de março e mais ao norte $\left(30^{\circ} \mathrm{S}\right)$ no mês de agosto, com uma tendência de um posicionamento mais ao sul no final do verão e mais ao norte no final do inverno (Figura $7 b$ ), provavelmente acompanhando a posição da confluência Brasil-Malvinas (Goni e Wainer, 2001). Entretanto, a alta amplitude entre os valores mínimos e máximos, tanto da latitude como da longitude inicial do desenvolvimento explosivo, indicam que as forçantes de baroclinia e de trocas de calor entre a superfície e atmosfera atuam conjuntamente e, dependendo da época do ano e da característica individual de cada sistema, uma forçante pode apresentar maior importância em relação à outra. Para a área restrita desse estudo, não foi encontrado $C E x$ ao norte de $27^{\circ} \mathrm{S}$.

\subsection{Variação da pressão central em $6 \mathrm{~h}$}

Essa seção apresenta uma análise da intensificação da $p_{c}$ a cada 6 h e do tempo de duração dos $C E x$ mês a mês. Essa análise é realizada com base nos $C E x$ identificados através do método $T N A_{r}$ (Equação 3) e calcula a $\Delta p_{c}$, ou seja, sem a consideração do campo de $p_{c l i}$. $\mathrm{O}$ fato do cálculo ser feito para $\Delta p_{c}$ não influencia significantemente os resultados dessa análise em específico, a qual aborda picos de intensificação e o tempo de duração dos $C E x$, porque em períodos de $6 \mathrm{~h}$ o 


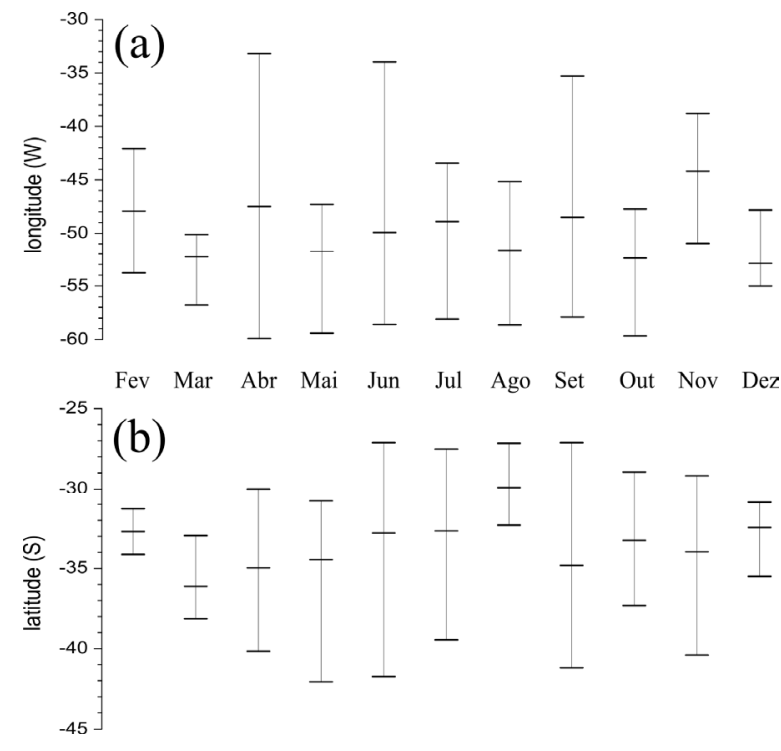

Figura 7 - (a) Longitude e (b) latitude média $(†)$, máxima $(T)$ e mínima $(\perp)$ inicial do desenvolvimento dos $C E x$ (identificados por $T N A_{r}$ ). A legenda dos meses é mostrada entre os dois gráficos.

deslocamento dos $C E x$ são relativamente pequenos (média de $300 \mathrm{~km}$ ). Percebe-se primeiramente que o tempo de duração desses sistemas é menor nos meses mais quentes e maior nos meses mais frios (Figura 8). Os CEx possuem duração de $24 \mathrm{~h}$ em fevereiro e março, de até $30 \mathrm{~h}$ em abril e novembro, de até $36 \mathrm{~h}$ em agosto, outubro e dezembro, de até $42 \mathrm{~h}$ em maio, julho e setembro e de até $48 \mathrm{~h}$ em junho. Esses períodos de duração, apresentados na Figura 8, são referentes exclusivamente às trajetórias explosivas e são considerados aqui como ciclo de vida dos $C E x$. Aproximadamente na metade desse ciclo de vida, ocorre a máxima intensificação, dada pela maior variação da $p_{c}$ em $6 \mathrm{~h}\left(\Delta p_{c} 6 \mathrm{~h}^{-1}\right)$. Apesar do pico de intensificação ocorrer aproximadamente no meio do ciclo de vida, nota-se através dos valores máximos plotados nos gráficos da Figura 8, que na maioria das vezes ocorre diminuição da $p_{c}$ ao longo de todo o ciclo de vida. A maior intensificação na metade do ciclo de vida dos $C E x$ é mais perceptível nos meses de abril a outubro e em dezembro (Figura 8). Nota-se ainda, que esse pico de intensificação apresenta tendência de ser mais pronunciado nos meses mais quentes, tais como, fevereiro, novembro e dezembro.

\subsection{Ciclones explosivos versus ciclones não explosivos.}

Nesta secção as estatísticas de média e o desvio padrão da profundidade $(D)$, pressão central $\left(p_{c}\right)$ e raio $(R)$ dos $C E x$ (identificados por $T N A_{r}$ ) foram comparadas com as estatísticas de toda a população de ciclones (ciclones não explosivos -
$C n E x)$, a qual não inclui os $85 C E x$ identificados nesse estudo. Além disso, compara-se os campos de velocidade de vento característicos aos $C E x$ com os campos de vento dos $C n E x$.

Percebe-se através da Figura 9a, que a média e o desvio padrão da $D$ dos $C n E x$ são maiores nos meses mais frios do ano (Figura 9a). Com relação a $p_{c}$ (Figura 9b) a média dos $C n E x$ apresenta dois picos de mínima, um em maio e outro em dezembro, enquanto que o desvio padrão em torno da média é relativamente maior nos meses mais frios. A climatologia do $R$ dos $C n E x$ (Figura 9c) mostra pouca variabilidade no decorrer do ano, com uma pequena tendência para existência de sistemas de maior escala espacial em maio. O desvio padrão em torno da média do $R$ é bastante elevado e isso não varia muito no decorrer do ano.

Quando se avalia os $C E x$, percebe-se que a variabilidade anual das estatísticas de média e desvio padrão não apresentam o mesmo comportamento encontrado para a climatologia dos $C n E x$. Entretanto, fica claro que a $D$ e $R$ médios dos $C E x$ são sempre maiores que as médias desses parâmetros encontrados em $C n E x$ (Figuras 9a e 9c). Essas diferenças mostraram que os $C E x$ são de 4,5 a 5,7 hPa mais profundos do que os $C n E x$, e que os $C E x$ apresentam $R$ de 0,22 a $0,59^{\circ}$ lat maior do que os $C n E x$. A $p_{c}$ dos $C E x$ é sempre menor do que a $p_{c}$ dos $C n E x$ (Figura 9b), com diferenças variando de 12,2 a 18,8 hPa. Ou seja, em média, os $C E x$ possuem maior escala espacial e são mais intensos que os $C n E x$.

Comparando as estatísticas de desvio padrão da $D$ (Figura 9a), observa-se que os valores entre a média e o desvio padrão abaixo (negativo) da média mensal dos $C E x$ são coincidentes com os valores entre a média e desvio padrão acima (positivo) da média mensal dos $C n E x$. Essa interseção de valores de desvio padrão é maior nos meses mais frios, mostrando que, principalmente no inverno, podem ocorrer $C n E x$ com $D$ observada em alguns $C E x$. Por outro lado, alguns ciclones, apesar de terem classificação de "explosivo", podem ter intensidade característica de $C n E x$ mais fortes. A interseção de valores dos desvios padrões também é percebida para as demais variáveis analisadas. No caso da $p_{c}$ (Figura 9b), isso é mais perceptível entre maio e agosto. No caso do $R$ (Figura 9c), a coincidência de valores ocorre o ano todo, podendo, inclusive, $\mathrm{o}$ desvio padrão positivo dos $C n E x$ coincidir com o desvio padrão positivo dos $C E x$. Também verifica-se que o $R$ médio dos $C n E x$ e $C E x$ podem apresentar valores muito próximos.

A velocidade do vento $(V)$ em torno do centro dos $C E x$ é maior no setor nordeste, com valores superiores a $14 \mathrm{~m} \mathrm{~s}^{-1}$, num raio de aproximadamente 4 a $8{ }^{\circ}$ lat (Figura 10a), no entanto esta área de ventos intensos se alonga pelo leste até o setor sul do $C E x$. A área na direção nordeste do centro dos ciclones é onde classicamente encontra-se o setor quente, na fase anterior à oclusão do sistema (Bjerknes e Solberg, 1922). Essa é a área em que o ar quente ascende devido ao avanço 

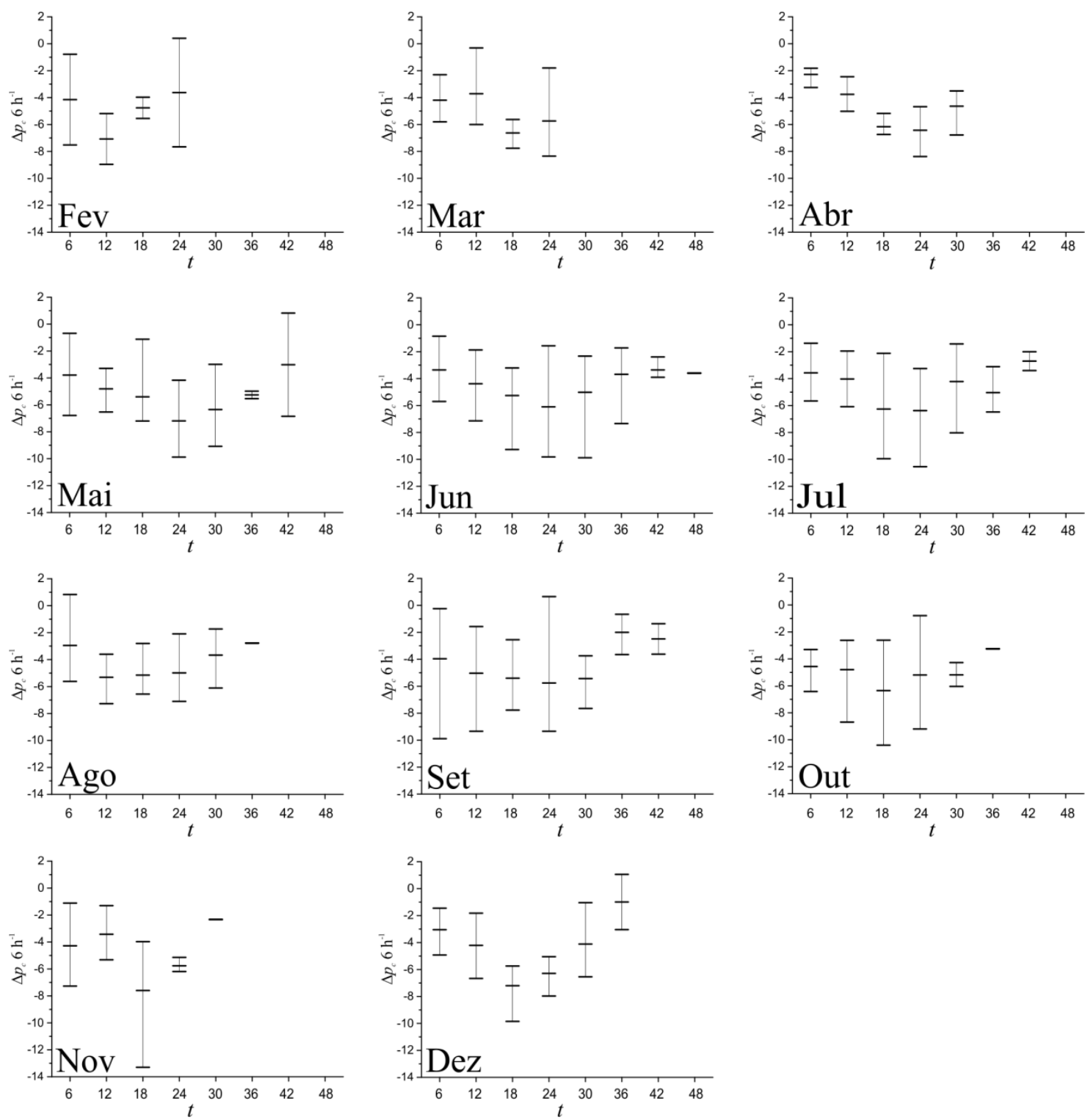

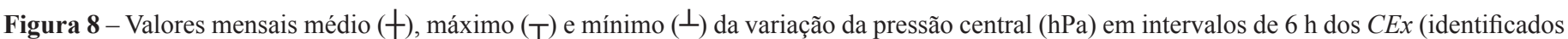
por $T N A_{r}$ e somente para o trecho de desenvolvimento explosivo). O mês é indicado no canto inferior esquerdo de cada painel. t é o tempo de vida do desenvolvimento explosivo.

do ar frio, contribuindo para a redução do setor quente, queda da pressão atmosférica e aumento da convergência horizontal (Bjerknes, 1919). A substituição do ar quente pelo ar frio induz ao decréscimo da energia potencial disponível do ciclone e aumento simultâneo de sua energia cinética. Próximo ao centro dos $C E x$ a $V$ decresce em direção ao centro do sistema, ficando em torno de $6 \mathrm{~m} \mathrm{~s}^{-1}$.

O campo de vento composto para os CnEx apresenta aproximadamente a mesma configuração espacial apresentada pelos $C E x$. O vento máximo em torno do centro dos sistemas, também encontra-se na direção nordeste do centro, onde classicamente localiza-se o setor quente (Figura 10b). Entretanto, os valores da $V$ máxima nessa área é de pouco mais de $10 \mathrm{~m} \mathrm{~s}^{-1}$.
O campo espacial da diferença percentual entre a $V$ de $C E x$ e $C n E x$ mostra que as maiores diferenças são percebidas entre as direções sudoeste e sudeste, passando pela direção norte do centro dos sistemas (Figura 10c). Onde classicamente é localizado o setor quente, os $C E x$ geram ventos de 40 a $50 \%$ mais intensos do que os $C n E x$. Mas, a maior diferença está na direção noroeste do centro dos sistemas, onde os $C E x$ geram ventos de aproximadamente $60 \%$ mais intensos que os $C n E x$.

\section{CONCLUSÕES}

Com base em metodologia objetiva de identificação e obtenção de estatísticas, apresentou-se nesse trabalho um 

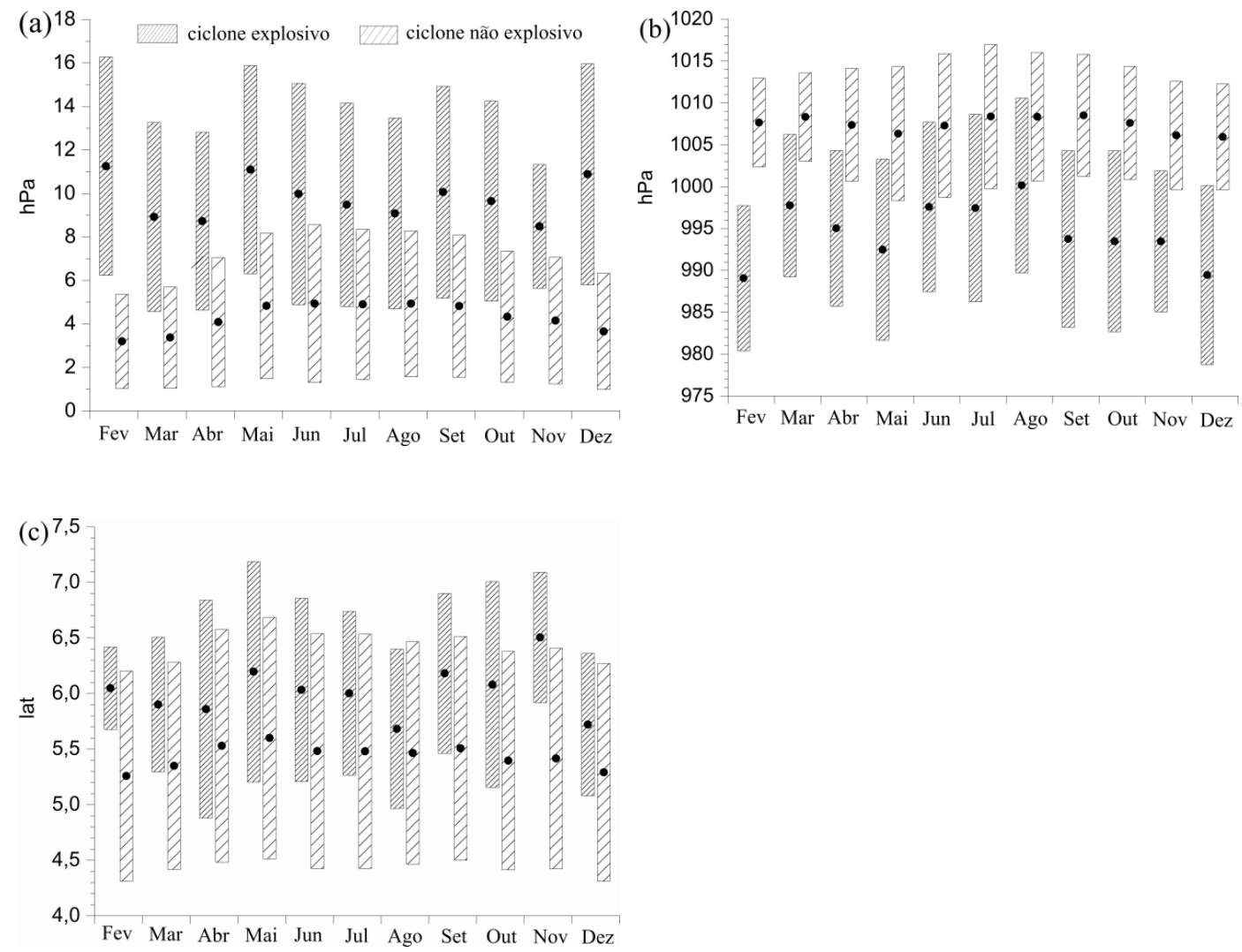

Figura 9 - Média (•) e desvio padrão (barras) mensal da (a) profundidade, (b) pressão central e (c) raio, para $C E x$ (identificados por $T N A_{r}$ ) e $C n E x$ (legenda no topo do primeiro gráfico).
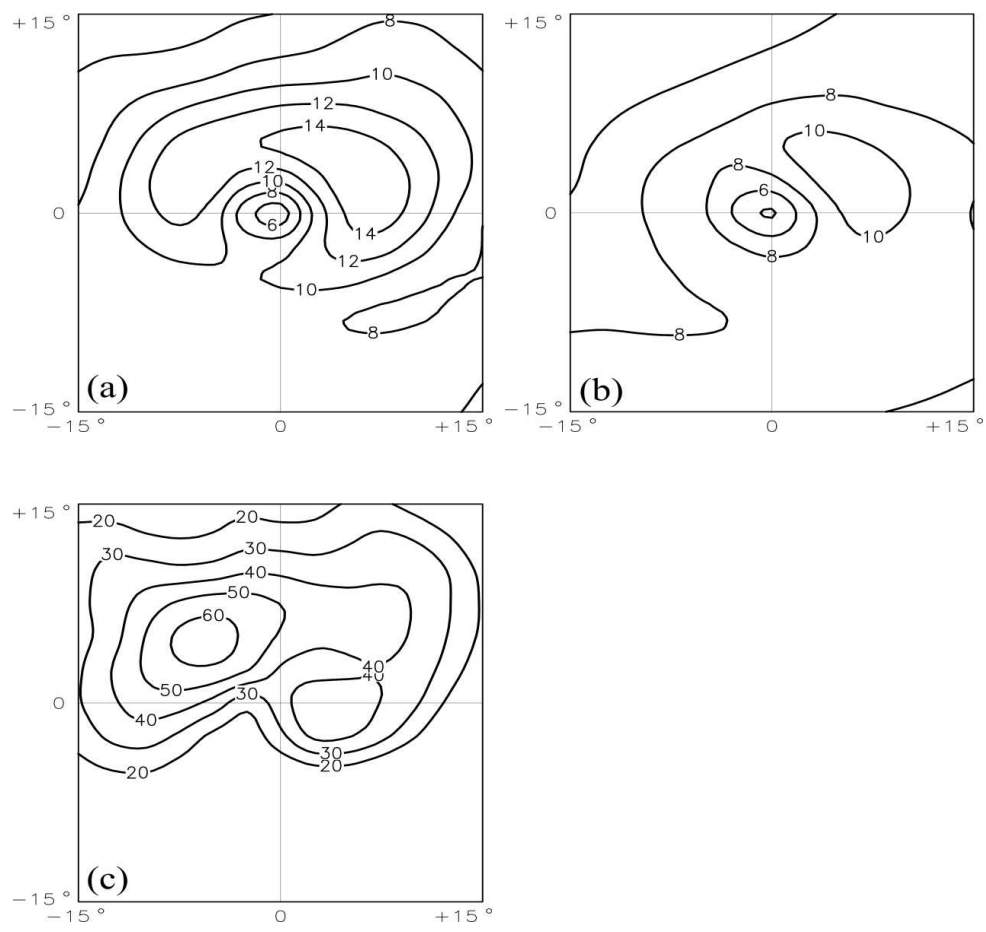

Figura 10 - Valores médios da velocidade do vento em torno do centro do sistema, calculados para (a) $C E x$ (identificados por $T N A_{r}$ ) e (b) $C n E x$. Isolinhas com intervalos de $2 \mathrm{~m} \mathrm{~s}^{-1}$. A diferença (\%) entre esses dois campos é apresentada no painel (c). Valores médios da velocidade do vento em torno do centro do sistema, calculados para (a) CEx (identificados por $T N A_{r}$ ) e (b) $C n E x$. Isolinhas com intervalos de $2 \mathrm{~m} \mathrm{~s}^{-1}$. A diferença (\%) entre esses dois campos é apresentada no painel (c). 
estudo climatológico de ciclogêneses explosivas para a região ciclogenética da América do Sul. Considerou-se como principais contribuições desse artigo, o detalhamento da climatologia dos ciclones explosivos para essa área restrita do globo e a comparação dos principais parâmetros desses sistemas com os sistemas ciclônicos de desenvolvimento não explosivo. Os dados de pressão foram da reanálise do NCEP/NCAR e a aplicação do método de Sanders e Gyakum (1980), mudando a pressão central do ciclone pela pressão central relativa, diminuiu de 144 para 85 o número de ciclogêneses explosivas identificadas no período de 1957 a 2010. Assim como, nas outras regiões do globo, o CEx na América do Sul é um fenômeno raro, com cerca de $4,1 \%\left(T N A_{c}\right)$ e $2,4 \%\left(T N A_{r}\right)$ de frequência entre todos os ciclones que se formam nessa área. Porém, embora raros, essa área ciclogenética da América do Sul é considerada a de maior frequência de $C E x$ do HS (Allen et al., 2010). De uma maneira geral, os resultados encontrados nesse estudo coincidem com os resultados encontrados por Lim e Simmonds (2002), que utilizaram outra base de dados.

A maior frequência de $C E x$ acontece nos meses mais frios, em junho, julho e agosto, com $47,1 \%$ dos casos. Dentro da área escolhida para esse estudo, os CEx se formam apenas ao sul de $27^{\circ} \mathrm{S}$ e a maioria dos sistemas, $72,9 \%$, apresentam início da trajetória com desenvolvimento explosivo sobre o oceano. Quase a totalidade dos CEx tem deslocamento para sudeste e a velocidade média desse deslocamento encontrada foi de $13,8 \mathrm{~m} \mathrm{~s}^{-1}$.

As comparações realizadas entre os parâmetros dos $C E x$ e CnEx permitiram algumas constatações importantes. A primeira delas é que as médias mensais da profundidade e do raio são sempre maiores em $C E x$ do que em $C n E x$. Os $C E x$ são de 4,5 a $5,7 \mathrm{hPa}$ mais profundos e possuem raio de 0,22 a $0,59^{\circ}$ lat maior que os $C n E x$. A pressão central dos $C E x$ é de 12,2 a $18,8 \mathrm{hPa}$ menor do que a pressão central dos $C n E x$. Os resultados desses parâmetros indicam que os $C E x$ são, em média, mais fortes e de maior escala espacial que os $C n E x$, apesar de existirem alguns $C n E x$ com profundidade, pressão central ou raio também observados em $C E x$ mais fracos. Por fim, a distribuição espacial da velocidade do vento em torno do centro dos sistemas mostrou que ambos $C E x \mathrm{e}$ $C n E x$ apresentam as maiores velocidades a nordeste do centro, onde classicamente encontra-se o setor quente. As maiores diferenças, entre os campos de velocidade dos $C E x$ e $C n E x$, encontram-se entre as direções sudoeste e sudeste, passando pela direção norte a partir do centro do sistema. Entretanto, na direção noroeste do centro a velocidade do vento provocada pelos $C E x$ é cerca de $60 \%$ mais forte que a velocidade do vento provocada pelos $C n E x$.

Sugere-se mais pesquisas envolvendo os $C E x$ que ocorrem na área ciclogenética da América do Sul, sendo particularmente interessante mostrar uma climatologia abordando a estrutura vertical, além de estudos sobre as estruturas dinâmica e termodinâmica responsável pelo desenvolvimento explosivo. Também é interessante identificar e detalhar as características dos $C E x$ que ocorrem sobre a área ciclogenética da América do Sul utilizando outras bases de dados.

\section{AGRADECIMENTOS}

Agradecemos ao "National Center for Envoronmental Prediction / National Center for Atmospheric Research" (NCEP/ NCAR) pelos dados meteorológicos. Também agradecemos aos pesquisadores Ian Simmonds e Kevin Keay pela assistência no uso do esquema de identificação de ciclones e aos revisores anônimos desse artigo pelas críticas úteis e construtivas. Agradecemos o suporte financeiro do CNPq (processo 471917/2008-7) e da FINEP (processo 2442008).

\section{REFERÊNCIAS BIBLIOGRÁFICAS}

ALlEN, J.T.; PEZZA, A.B.; BLACK, M.T.. Explosive cyclogenesis: A global climatology comparing multiple reanalysis. Journal of Climate, v. 23, n. 24, p.6468-6484, 2010.

BITENCOURT, D.P.; ACEVEDO, O.C.; GAN, M.A.; FUENTES, M.V.; MUZA, M.N.; RODRIGUES, M.L.; QUADRO, M.F.L.. Relating winds along the Southern Brazilian coast to extratropical cyclones. Meteorological Applications, v. 18, n. 2, p.223-229, 2011.

BJERKNES, J.. On the structure of moving cyclones. Geofysiske Publikationer, v. 1, n. 2, p.1-8., 1919.

BJERKNES, J.; SOLBERG, H.. Life cycle of cyclones and the Polar Front theory of atmospheric circulation. Geofysike Publikationer, v. 3, n. 1, p.3-18, 1922.

CHEN, G.T.J.; LU, C.F.. On the climatological aspects of explosive cyclones over the Western North Pacific and East Asia Coastal areas. Terrestrial, Atmospheric and Oceanic Sciences, v. 8, n. 4, p.427-442, 1997.

CHEN, S.J.; KUO, Y.H.; ZHANG, P.Z.; BAI, Q.F.. Climatology of explosive cyclones of the East Asian Coast. Monthly Weather Review, v. 120, n. 12, p.3029-3035, 1992.

COLLUCI, S.J.; ALBERTA, T.L.. Planetary-Scale Climatology of explosive cyclogenesis and blocking. Monthly Weather Review, v. 124, n. 11, p.2509-2520, 1996.

CRESCENTI, G.H.;WELLER, R.A.. Analysis of surface fluxes in the marine atmospheric boundary layer in the vicinity of rapidly intensifying cyclones. Journal of Applied Meteor. ology, v. 31, p.831-848, 1992.

DAVIS, C.A.; EMANUEL, K.A.. Observational evidence for the influence of surface heat fluxes on rapid maritime 
cyclogenesis. Monthly Weather Review , v. 116, n. 12, p.2649-2659, 1988.

GAN, M.A.; RAO, V.B.. Surface cyclogenesis over SouthAmerica. Monthly Weather Review, v. 119, n. 5, p 1293-1302, 1991.

GAN, M.A.; RAO, V.B.. The influence of the Andes Cordillera on transient disturbances. Monthly Weather Review, v. 122, n. 6, p.1141-1157, 1994.

GONI, G.J.; WAINER, I.. Investigation of the Brazil Current front variability from altimeter data. Journal of Geophysical Research, v. 106, n. C12, p. 31,117-31,128, 2001.

GYAKUM, J.R.; DANIELSON, R.E.. Analysis of meteorological precursors to ordinary and explosive cyclogenesis in the Western North Pacific. Monthly Weather Review, v. 128, p.851-863, 2000.

HOSKINS, B.. A potential vorticity view of synoptic development. Meteorological Applications, v. 4, n. 4, p.325-334, 1997.

HOSKINS, B.J.; HODGES, K.I.. A new perspective on Southern Hemisphere storm tracks. Journal of Climate, v. 18, n. 20, p.4108-4129, 2005.

JONES, D.A.; SIMMONDS, I.. A climatology of Southern Hemisphere extratropical cyclones. Climate Dynamics, v. 9, n. 3, p.131-145, 1993.

JUSEM, J.C.; ATLAS, R.. Diagnostic evaluation of numerical model simulations using the tendency equation. Monthly Weather Review, v. 119, n. 12, p.2936-2955, 1991.

KALNAY, E.; KANAMITSU, M.; KISTLER, R.; COLLINS, W.; DEAVEN, D.; GANDIN, L.; IREDELL, M.; SAHA, S.; WHITE, G.; WOOLLEN, J.; ZHU, Y.; CHELLIAH, M.; EBISUZAKI, W.; HIGGINS, W.; JANOWIAK, J.; MO, K.C.; ROPELEWSKI, C.; WANG, J.; LEETMAA, A.; REYNOLDS, R.; JENNE, R.; JOSEPH, D.. The NCEP/ NCAR 40-year reanalysis project. Bulletin of the American Meteorological Society, v. 77, n. 3, p.437-471, 1996.

KOUROUTZOGLOU, J.; FLOCAS, H.A.; KEAY, K.; SIMMONDS, I.; HATZAKI, M.. Climatological aspects of explosives cyclones in the Mediterranean. International Journal of Climatology, v. 31, n. 12, p.1785-1802, 2010.

KUO, Y-H.; LOW-NAM, S.. Prediction of nine explosive cyclones over the western Atlantic Ocean with a regional model. Monthly Weather Review, v. 118, n. 1, p.3-25, 1990.

KUO, Y-H.; REED, R.J.; LOW-NAM, S.. Effects of surface energy during the early development and rapid intensification stages of seven explosive cyclones in the Western Atlantic. Monthly Weather Review, v. 119, n.2, p.457-476, 1991.

LACKMANN, G.M.; BOSART, L.F.; KEYSER, D.. Planetaryand synoptic-scale characteristics of explosive wintertime cyclogenesis over the Western North Atlantic Ocean. Monthly Weather Review, v. 124, p.2672-2702, 1996.
LIM, E.P.; SIMMONDS, I.. Explosive cyclone development in the Southern Hemisphere and a comparison with Northern Hemisphere Events. Monthly Weather Review, v. 130, n. 9, p.2188-2209, 2002.

LUPO, A.R.; SMITH, P.J.; ZWACK, P. A diagnosis of the explosive development of two extratropical cyclones. Monthly Weather Review, v. 120, n. 8, p.1490-1523, 1992.

MANOBIANCO, J.. Explosive east coast cyclogenesis over the west-central North Atlantic Ocean: A composite study derived from ECMWF operational analysis. Monthly Weather Review, v. 117, n. 11, p.2365-2383, 1989a.

MANOBIANCO, J.. Explosive east coast cyclogenesis: Numerical experimentation and model-based diagnostics. Monthly Weather Review, v. 117, n. 11, p.2384-2405, 1989b. MENDES, D.; SOUZA, E.P.; TRIGO, I.F.; MIRANDA, P.M.A.. On precursors of South American cyclogenesis. Tellus A, v. 59, 1, p.114-121, 2007.

MENDES, D.; SOUZA, E.P.; MARENGO, J.A.; MENDES, M.C.D.. Climatology of extratropical cyclones over the South American-southern oceans sector. Theoretical and Applied Climatology, v. 100, n. 3-4, p.239-250, 2010.

MIKY-FUNATSU, B.; GAN, M.A.; CAETANO, E.. A case study of orographic cyclogenesis over South America. Atmósfera, v. 17, n. 2, p.91-113, 2004.

MURRAY, R.J.; SIMMONDS, I.. A numerical scheme for tracking cyclone centres from digital data. Part I: Development and operation of the scheme. Australian Meteorological Magazine, v. 39, p.155-166, 1991.

NEIMAN, P.J.; SHAPIRO, M.A.. The life cycle of an extratropical marine cyclone. Part I: Frontal-cyclone evolution and thermodynamic air-sea interaction. Monthly Weather Review, v. 121, n. 8, p.2153-2176, 1993.

NUSS, W.A.; ANTHES, R.A.. A numerical investigation of lowlevel processes in rapid cyclogenesis. Monthly Weather Review, v. 115, n. 11, p.2728-2743, 1987.

PEZZI, L.P.; SOUZA, R.B.; ACEVEDO, O.C.; WAINER, I.; MATA, M.M.; GARCIA, C.A.E.; CAMARGO, R.. Multiyear measurements of the oceanic and atmospheric boundary layers at the Brazil-Malvina confluence region. Journal of Geophysical Research, v. 114, p. 1-19, 2009.

PIVA, E.D.. Estudo de caso sobre o papel dos fluxos de calor latente e sensível em superfície em processos de ciclogênese de costa leste ocorrido na costa da América do Sul. 2001. 162 f. Tese (Doutorado em Meteorologia) - INPE-8498-TDI/781, INPE, São José dos Campos, Brasil, 2001.

PIVA, E.D.; MOSCATI M.C.L.; GAN M.A. Papel dos fluxos de calor latente e sensível em superfície associado a um caso de ciclogênese na costa leste da América do Sul. Revista Brasileira de Meteorologia, v. 23, n. 4, p.450476, 2008. 
PIVA, E.; GAN, M. A.; MOSCATI, M. C. L.. The role of latent and sensible heat fluxes in an explosive cyclogenesis over South America. Journal of the Meteorological Society of Japan, 89(6), 1-27, 2011, DOI:10.2151/jmsj.2011-604.

REBOITA, M.S.. Ciclones estratropicais sobre o Atlântico Sul: Simulação climática e experimentos de sensibilidade. IAGUSP: São Paulo, Brasil; 359 pp., 2008.

ROEBBER, P.J.. Statistical analysis and updated climatology of explosive cyclones. Monthly Weather Review , v. 112, n. 8, p.1577-1589, 1984.

SANDERS, F.. Explosive cyclogenesis in the West-Central North Atlantic Ocean, 1981-84. Part I: Composite structure and mean behavior. Monthly Weather Review, v. 114, n. 10, p.1781-1794, 1986.

SANDERS, F.; GYAKUM, J.R.. Synoptic-dynamic climatology of the "Bomb". Monthly Weather Review, v. 108, n. 10, p.1589-1606, 1980.

SARAIVA, J.M.B.. Previsão de tempo na Região Sul: Efeitos Locais e Influência da Liberação de Calor Latente. 1996. 322 f. Tese (Doutorado em Meteorologia) - IAG-USP, São Paulo, 1996.

SATYAMURTY, P.; SANTOS, R.P.; LEMS, M.A.M.. On the stationary trough generated by the Andes. Monthly Weather Review, v. 108, n. 4, p.510-520, 1980.

SELUCHI, M.; SAULO, A.C.. Possible mechanisms yielding an explosive coastal cyclogenesis over South America: experiments using a limited area model. Australian Meteorological Magazine, v. 47, n. 4, p.309-320, 1998.

SELUCHI, M.; SERAFINI, Y.V.; LE TREUT, H.. The impact of the Andes on transient atmospheric systems: A comparison between observations and GCM results. Monthly Weather Review , v. 126, n. 4, p.895-913, 1998.

SIMMONDS, I.; KEAY, K.. Variability of Southern Hemisphere extratropical cyclone behavior, 1958-1997. Journal of Climate, v. 13, n. 3, p.550-561, 2000a.

SIMMONDS, I.; KEAY, K.. Mean Southern Hemisphere extratropical cyclone behavior in the 40-Year NCEP-NCAR reanalysis. Journal of Climate, v. 13, n. 5, p.873-885, $2000 \mathrm{~b}$.
SIMMONDS, I.; MURRAY, R.J.. Southern extratropical cyclone behavior in ECMWF analyses during the FROST special observing periods. Weather and Forecasting, v. 14, n. 14, p. 878-891, 1999.

SIMMONDS, I.; MURRAY, R.J.; LEIGHTON, R.M.. A refinement of cyclone tracking methods with data from FROST. Australian Meteorological Magazine, v. Special Edition, p.35-49, 1999.

SIMMONDS, I.; WU, X.. Cyclone behavior response to changes in winter Southern Hemisphere sea-ice concentration. Quarterly Journal of the Royal Meteorological Society, v. 119, n. 513, p.1121-1148, 1993.

SINCLAIR, M.R.. An Objective cyclone climatology for the Southern Hemisphere. Monthly Weather Review, v. 122, n. 10, p.2239-2256, 1994.

SINCLAIR, M.R.. A climatology of cyclogenesis for the Southern Hemisphere. Monthly Weather Review, v. 123, n. 6, p.1601-1619, 1995.

SINCLAIR, M.R.. Objective identification of cyclones and their circulation intensity, and climatology. Weather and Forecasting, v. 12, n.3, p.595-612, 1997.

SMITH, P.J.. The importance of the horizontal distribution of heating during extratropical cyclone development. Monthly Weather Review, v. 128, n. 10, p.3692-3694, 2000.

VERA, C.S.; VIGLIAROLO P.K.; BERBERY E.H.. Cold season synoptic scale waves over subtropical South America. Monthly Weather Review, v. 130, n. 3, p.684-699, 2002.

WANG, C.C.; ROGERS, J.C.. A composite study of explosive cyclogenesis in different sectors of the North Atlantic. Part I: Cyclone structure and evolution. Monthly Weather Review, v. 129, n. 6, p.1481-1499, 2001.

YOSHIDA, A.; ASUMA, Y.. Structures and environment of explosively developing extratropical cyclones in the Northwestern Pacific region. Monthly Weather Review, v. 132, n. 5, p.1121-1142, 2004.

YOSHIDA, A.K.; ASUMA, Y.. Numerical study of explosively developing extratropical cyclones in the Northwestern Pacific region. Monthly Weather Review, v. 136, n. 2, p.712-740, 2008. 